\title{
The use of interactive storytelling, cartoon animation and educational gaming to communicate the biblical message to preschool children
}

Author:
Dirk G. van der Merwe ${ }^{1}$
Affiliation:
'Department of New
Testament, Faculty of
Theology, North-West
University, Potchefstroom,
South Africa
Corresponding author:
Dirk G. van der Merwe,
dirkvdm7@gmail.com
Dates:
Received: 30 Apr. 2020
Accepted: 28 Aug. 2020
Published: 20 Nov. 2020
How to cite this article:
Van der Merwe, D.G., 2020,
'The use of interactive
storytelling, cartoon
animation and educational
gaming to communicate the
biblical message to preschool
children', HTS Teologiese
Studies/Theological Studies
76(2), a6074. https://doi.
org/10.4102/hts.v76i2.6074
to read online.
Copyright:
Read online:
@ 2020. The Authors.
Licensee: AOSIS. This work
is licensed under the
Creative Commons
Attribution License.

This article focuses on how biblical content and spiritualities can be communicated, probably more effectively, to (late) preschool children by using information technology, which has already been implemented successfully for years in secular and religious environments. Because children enjoy listening to stories, watching cartoons and playing every day, the approach in this research will be to propose a particular construct to communicate biblical content to preschool children. This construct comprises interactive storytelling, cartoon animation and educational gaming, which constitute a trilogy for teaching biblical content and principles to preschool children. This should be done interactively. These three approaches have become fundamental designs and presentations in child education. Churches, Christian nurseries and other Christian educators, in general, are encouraged to develop computer programs according to the construct and strategy proposed in this article for the teaching of the Gospel to late preschool children. The approach in this article will be, firstly, to examine and explore the religious orientation of preschool children and, secondly, to validate and propose how computer technology can be implemented to communicate the biblical content to preschool children via the trilogy of interactive storytelling, cartoon animation and educational gaming in an uninterrupted experience.

Contribution: This article argues that the use of interactive storytelling, cartoon animation and educational gaming should be used consecutively and uninterruptedly to communicate the biblical message to preschool children. This is probably the most effective way to keep the attention of these children and to affect their conduct.

Keywords: Cartoon; Children; Storytelling; Technology; Preschool.

\section{Introduction}

Throughout human history certain technologies ${ }^{1}$ have become significant metaphors through which the sciences, philosophy, literature and theology of specific societies understood reality. ${ }^{2}$ Today's computer technology can be regarded as the matrix in contemporary technology. The powerful influence of computers has consequently changed the ways of communication and thinking. This dual aspect (ways of communication and thinking) has become part of the communication discourse and the medium of the discourse shaping cultural conventions and myths ${ }^{3}$ about 'truth', which had become arbitrary (cf. Shaffer 2006:10). ${ }^{4}$

The truth in the Bible also received relative status in this postmodern era because of critique from the sciences and theological liberalism. ${ }^{5}$ In contrast to this relativity status, there are still many voices that regard the Bible to contain God's speech. In general, parents and educators who accept

1.See Kolawole (2019:1-2) and Sims (n.d.:3-5) on defining 'technology'. In this article it is used in the context of 'a method of or machine for doing something that is created by technology' (Merriam-Webster 2020, https://www.merriam-webster.com/dictionary/ technology).

2.See Floridi (2014) on How the infosphere is reshaping human reality.

3.'Cultural myths are defined as networks of beliefs and values, and they have the potential of influencing science and science education' (Tippins, Nichols \& Kemp 1999:1)

4.See also Mumford ([1934] 2010). According to Noble (1997:5), 'Scientists and technologists increasingly attest publicly to the value of their work in the pursuit of divine knowledge'. Stahl (1999), 2 years later, linked technology with mysticism, experiencing the divine in technology. Then see Davies (2019:19-20), who opposes the reasoning of Noble and Stahl, who connect technology widely with religion or even in a narrow sense with mysticism.

5.'Theological liberalism is the attempt to adapt religious ideas to modern culture and ways of thinking while simultaneously rejecting any conviction that God has revealed Himself to human beings in time through scripture with any kind of reliability or accuracy' (Mohler 2020, https://www.monergism.com/topics/bad-theology/liberal-theology).

Note: Special Collection entitled Christianity as Change Agent in the 4th Industrial Revolution World, sub-edited by Erna Oliver (UNISA). 
that the Bible consists of truth about God deem it necessary and axiomatic that biblical content and principles also be communicated to preschool children. Many preschool children, with Christian parents, already encounter the Bible at home, the church and Christian nurseries, where they are introduced to biblical content at elementary level. At home, Christian parents will habitually read biblical stories from a special Bible for children before their children go to bed. The daily programmes of most Christian nurseries normally start with prayer and 'story' ${ }^{6}$ reading from the Bible. On Sundays, Sunday school teachers will communicate, according to a prescribed syllabus, the content of the Bible to preschool children through storytelling.

Computer usage by preschool children is becoming increasingly common. Many families allow these children to access, engage with and enjoy web-based interactive games and activities exclusively designed for specific age groups of children. In addition, handheld devices, like mobile phones and tablets, are more frequently used in family environments. In this way, the use of technology influences and shapes the development of children (Parette \& Blum 2013:2). However, more and more evidence $^{7}$ emerges for the use of information technology to support the learning of young (preschool) children with regard to 'writing, communication, social behaviour and play' (Parette \& Blum 2013:6). In this article, the objective will be to propose a particular construct and strategise how computer technology can be used to communicate the biblical message, probably more effectively, to preschool children.

In order to achieve this, an extended approach is proposed. The modus operandi in this article, because of its focus on preschool children, will be to firstly look into the religious orientation of preschool children and, secondly, propose how computer technology can be used to communicate the biblical content to preschool children via the trilogy of interactive storytelling, cartoon animation and educational gaming in an uninterrupted experience.

\section{Faith and spiritual development in preschool children}

The notion that children are spiritual is not something new. Generally speaking, children are perceived to have a 'natural and uncritical faith, a natural wisdom and capacity for discerning the way things really are' (my italics; Roehlkepartain, King \& Benson 2006:9).

\section{Faith development}

\section{Structural development system}

According to Jones (2004:345), during the latest decades of the previous century, the structural-developmental model of faith, as advised by James Fowler, was respected as the major paradigm for faith-development studies. Fowler constructed

6.Used in the sense of 'an account of incidents or events' (Merriam-Webster, viewed 23 July 2020, from https://www.merriam-webster.com/dictionary/story).

7.See the vast amount of academic and popular publications and YouTube programmes on the internet. his 'faith development theory' on the concept of 'discontinuous stages of spiritual development'. This theory relates to the 'theory of cognitive development' as developed by Jean Piaget, the 'theory of psychosocial development' of Erik Erikson and also the 'theory of moral development' developed by Laurence Kohlberg. These three models acknowledged children to have the capacity to progress in their development to maturity from concrete to abstract thinking. According to Moore et al. (2016:2), Fowler locates 'the stages of spiritual development within these developmental models, suggesting that, as children mature, they have an increased ability to become more aware and engaged with their spirituality'. After a thorough investigation of the stage development of Fowler, Jones concluded that it fails to describe Christian faith development. ${ }^{8}$ According to Jones (2004:345), notwithstanding the supremacy of Fowler's theory, Christian educators, ${ }^{9}$ in particular within Evangelical circles, constantly questioned the congruency of Fowler's perception of faith with Christian faith. For Jones (2004:354) it 'rather, describes the broader psychical context by which Christian faith is affected' and 'from which Christian faith-development remains distinguishable'. Jones (2004:354) concluded that Christian faith development, cannot happen in a 'psychical vacuum'. ${ }^{10}$ There is a need to include a Christian faith orientation in any definition of faith development.

\section{Relational development system: Conceptualising God}

Advocates of the 'spiritual child movement' detached the development of preschool children from 'traditional stagestructural cognitive-based theories' (Moore et al. 2016:2). Empirical research has revealed the limits of stage theories, and hence, 'relational developmental systems perspectives' increased in acceptance. These relational theories highlighted that 'ontogeny ${ }^{11}$ occurs through mutually influential relations between individuals and the many levels of the bioecology in which they are embedded across time' (King \& Bouatzis 2015:982). Human development is a holistic process 'biological, psychological, social, cultural' - and also includes a person's spiritual development (cf. King \& Bouatzis 2015:982).

Today, 'relational developmental systems' metatheory, is the most prominent and accepted structure in developmental science (see also, Johnson et al. 2013:66-94; Overton 2013: 94-107). As a metatheory, relational developmental systems postulates how behaviours integrate with one another and what instigates the change of behaviour, and it reflects on the methods to be used to examine human development. The essence of relational developmental systems metatheory is founded on the notion that development is generated via the interactions of individuals with their contexts. Bearing

8.According to Jardine and Viljoen (1992:83) this strategy was wrong even though it was a 'major breakthrough in the integration of religion and psychology'.

9. Refers to parents and teachers at Christian nurseries and the Church.

10.See also the evaluative discussion of Fowler's theory of faith development by Jardine and Viljoen (1992:74-78).

11.'The development of an individual organism or anatomical or behavioural feature from the earliest stage to maturity' (Oxford Dictionary, https://www.lexico.com/ definition/ontogenesis). 
this in mind, human behaviour then cannot disconnectedly be explained from either the context or the individual. The only viable explanation can be when the relations between both the individual and various contexts are respected (cf. Ettekal et al. 2017:650). Such contexts can include familial, social and spiritual contexts.

According to Moore et al. (2016:9), preschool children who are more exposed to spiritual and religious interactions may experience a more purposefully cultivated and encouraged spiritual life. This insinuates that these preschool children can generate a better perception of 'concepts related to duality and may draw distinctions between human and divine properties' (Moore et al. 2016:9). Consistent groundwork of the 'spiritual child movement' has shown that children tend to engage more with their spirituality than was the overall conception previously. Therefore, the 'ability for spiritual engagement' of preschool children should not be underestimated (Moore et al. 2016:9). According to this information, it can be deduced that concepts of God can be constructed early in life and can later influence their religious preferences. At this point, the relationships of preschool children with their parents and nursery teachers are fundamental to their faith and spiritual development. Preschool children spend most of their time at home and consequently are more dependent on their parents.

Even differences in cultures should not be an obstacle for preschool children. Lin, Zhang and McBride-Chang (2010:3) referred to Vygotsky (1978), who wrote that children, irrespective of their cultures (my insertion for clarity), can 'optimally develop in learning' when a more competent person in their development zone is present. In their early years of development, preschool children are mostly facilitated by competent partners who are mostly parents and family members. ${ }^{12}$ During childhood, the attachment of these children to caregivers can also be regarded as imperative to cognitive and relational development.

A formidable transition is made when preschool children enter Christian nurseries for the first time, which is when their home context is replaced by the school context. Both environments and circumstances undoubtedly can affect the religious development of these preschool children. In this role, the teacher-child relationship has also to be regarded as equally important, although these children consider teachers of Christian nurseries as a 'secondary attachment figure' (De Roos 2006:87; also cf. De Roos, Miedema \& Iedema 2010:27). Hence, both parents and teachers add to distinctive variances about the concepts of God amongst preschool children, although in different ways.

According to her extensive research, De Roos et al. (2010:27) found, surprisingly and contrary to her anticipation, that the concept of God of preschool children did not resemble more to their parents' concept of God than to the concept of their teachers. The influence and results of the concept of God of parents and teachers varied from the concept of God of children, depending on the kind of concept of God in consideration. On the one hand, the parental environment seems to influence, in particular, the relational component of the preschool children's concept of God (God is a loving friend). On the other hand, teachers influence, in particular the concept of God of these preschool children using biblical content. This understanding and interpretation may be verified by the diverse positions of parents versus teachers in the lives of these children (De Roos et al. 2010):

$[N]$ urture, love and care are typical characteristics of the parentchild relationship, while instruction in myths and belief systems is more typical for religious education by teachers in the classroom. (p. 27)

In this way, both parents and teachers contribute in a unique way to a child's individual differences concerning the conceptualisation of God.

When preschool children have a tensed or diminishing relationship with their teachers, a related, negative concept of God can develop, whilst children having positive relationships with their teachers can develop a positive concept of God (De Roos 2006:88). De Roos connected more ideal teacher-child relationships to a more loving concept and experience of God in Christian nurseries. Her research also proved that preschool children who had an intimate, accessible and congruent relationship with their teacher indicated 'positive emotions, high involvement in groups and had high self-esteem, which led to a loving, caring God concept' (De Roos 2006:92).

Fosarelli (2003:4) deemed to be more specific about the relations between parents and preschool children. He points out that, for preschool children, associations and projections play a fundamental role in their lives. It helps them to make sense of their world and God. For them, they project their parents' (or important adults) attributes onto God to make sense of God. If a parent is angry when the child did anything wrong, the child will project it on God who would then also be angry. On the other hand, these children will also project the positive attitudes and conduct of their parents onto God (Fosarelli 2003:4). To live in a relationship with God fosters the expectancy that God will be good to them. When they behave well, they normally expect things to go well. They parallel this with how they treat their friends. They normally expect of friends to treat them well, equivalent to how they treat them. They regard God as a friend and sincerely a mighty one indeed (Fosarelli 2003:5).

From the given data it can be deduced that, in family and nursery discourse, with regard to faith development, preschool children are indeed 'active participants rather than passive recipients' to the beliefs shared with them by their parents and teachers (cf. King \& Bouatzis 2015:988). Thus, a fluent interaction between parents or teachers and these preschool children may have a dynamic effect on the religious development of these children. 
A mutual influence exists between a person's concept of God and how that person will interpret and understand the Bible, and reciprocally, how the reading, interpretation and comprehension of the Bible can influence a person's construction of God's image. This is also true of preschool children. In the previous section, I have briefly discussed the faith orientation of preschool children in terms of a relational development system. The interconnectedness of parents, teachers and caregivers is shown to be a significant contributor to the preschool children's concept of God. Their faith orientation and concept of God will significantly determine how they will receive and understand the biblical stories communicated to them. ${ }^{13}$

On the other hand, their understanding of biblical stories carries a significance and equal importance for them conceptualising God. It is proposed that the following trilogy of communication can certainly influence their clarity, perception of the Bible and consequently the development (even amendment) and formation of their concept of God. The following paradigm of communication, as proposed in this article, can facilitate them to understand these stories much better and sharper: it will be conducted in terms of interactive storytelling, cartoon animation and educational gaming.

\section{Communicating the biblical content to preschool children Considering perception and cognition}

For a person to experience some kind of spirituality necessitates some form of 'cognitive ability' to become conscious of the bigger picture of life. The person will then realise that there is something much more and much bigger than what the senses can capture. This ability, according to Roehlkepartain et al. (2006:9), already exists in a person's early childhood years, as young as 4 years in some cases, but definitely at the age of 6 years. For a spirituality to develop in preschool children, encouragement and support is needed. As they grow older these concepts become more differentiated because of their denominational differences. In their cognition of religion, they attend to the most significant features of their experiences. They will develop their own religious concepts subjectively because for many of them certain religious concepts are unfamiliar (Ratcliff 1988:9). Consequently, the idea of using appropriate 'examples' is a necessity when new concepts are formed in religious education of preschool children (also cf. Kuther 2016:499). Concrete descriptions are crucial for the development of basic concepts. Concepts should also be based on previous experience with basic concepts relating to concrete objects (Kuther 2016:485-488). It is here where animated cartoon videos and educational games can have a major 13.Storytelling is for the child like reading the Bible. educational function to put objects and action in antiquity into perspective to make it more perceivable. ${ }^{14}$

\section{Kind of material}

Ratcliff (1988:28) indicated that sometimes clues to the kind of material (content) to be used, excluded or even modified occur in the text (language) itself. Parables, symbols, metaphors or other kinds of language ${ }^{15}$ require multiple levels of understanding, which appear to be inappropriate or incomprehensible for preschool children. Any gruesome or misleading pictures or activities should also be prohibited. ${ }^{16}$ On the one hand, according to Ratcliff (1988:28), there is a lack of knowledge about the abilities of preschool children, what they can and what they cannot understand of the Bible. On the other hand, the abilities of preschool children must not be underestimated.

The way in which biblical content is communicated (taught) should be considered within the developmental framework of these children. The stage of cognitive development of preschool children should be considered when analysing and communicating the content of the Bible. This implies that the team (Christian educators and cartoon animation experts) who should construct the religious programmes needs to carefully study the biblical content and the religious conceptuality of these preschool children before communicating any biblical content with these children.

\section{Stories and interactive storytelling ${ }^{17}$}

For millennia, storytelling has (Haven 2007):

[E]volutionarily rewired the human brain to be predisposed to think in terms of story and to use story structure to create meaning and to make sense of events and other's actions. (p. 5) ${ }^{18}$

Most preschool children love stories. This is a natural preference for them everywhere. It is common for parents to allow preschool children to watch stories on television,

14.In this preschool stage, children begin using 'signs and symbols' to connote it to objects in everyday life. Although they are already competent to think categorically, they are incompetent to understand and distinguish different categories from each other. They are equally incompetent to realise that individuals or objects can be classified into multiple categories simultaneously (Bridges \& Moore 2002:5).

15.Lin et al. (2010:2) stated explicitly that '[I]iteracy acquisition and development [of preschoolers] differ dramatically across different cultures'. The researcher is very much aware of this and is writing from a South African perspective, where this is evident regarding English as the principal language.

16.Vander Stichele and Pyper (2012), in Text, Image, and Otherness in Children's Bibles, indicate that violent cartoons or cartoons in Children's Bibles that incorrectly refer to Bible content can lead to violent and negative conduct in the personal lives of small children. Thus, very young children who are fed with cartoon images of violence are more prone to be influenced negatively than others. See articles of Rogers and Fewell (2012:123-152) and Dupertuis (2012:271-290). This does not mean that cartoon picturing is bad for conveying information. We have to distinguish between medium, form and content, which are different entities.

17. Of course, one must bear in mind that there will always be idiosyncrasies - children with disabilities, children in cities compared with those in rural areas and children of different cultures. In this article, the 'most ideal' circumstances are imagined. It is just impossible to address these variances in an article with limited length.

18.'A story is a narrative account of an event or a sequence of events. The message the story tells, must be true. It must be consistent and authentic. A story adds emotion, characters and sensory details to plain facts. That's why a story grabs us, pulls us along its plot and delivers its key message powerfully', http://www.frogleaps.org/ along its plot and delivers its key message powerfully', http://www.frogleaps.org/
blog/topic/what-is-a-story-and-what-is-storytelling/. This is what is meant by storytelling in this article. 
YouTube or DVDs. Storytelling can be regarded as one of the oldest and most powerful forms of teaching and generates great enjoyment in these children. This then mandates stories to be a fundamental mechanism of religious education amongst preschool children (Ratcliff 1988:247).

Regarding the faith development ${ }^{19}$ of preschool children, it can be said that they specifically love 'myths', stories of beings superior to normal life, especially stories that deal with the basics of human affairs. The most appreciated 'myths' and stories are those in which good beings (persons or animals) triumph over evil. They love listening to stories from their faith tradition, coming from the Bible. The more dramatic and astonishing the story is, the better for them. The children believe these stories. For them the stories are not only possible but also believable (Fosarelli 2003:5). In fact, stories offer many excellent benefits for preschool children and early school-age children. In the subsequent sections, I discuss Haven (2007:90-95) and Myers (2012).

\section{Advantages of stories}

Stories improve language skills: When listening to storytellers, preschool children have the opportunity to hear words spoken to them in a dramatic and distinctive way. They hear new words and variations in speech intonation and articulation, from which they benefit in expanding their (religious) vocabulary. Although these children do not know or are not even aware of the literary features of storytelling, it contributes over time to shape their thinking, reasoning and communication of biblical content.

Stories boost memory: Storytelling does not make use of illustrations, as in books, and so children have to remember the names of characters, events and interactions in the story. This assists in exercising the memory skills of preschool children. Preschool educators should incorporate interactivities that involve asking questions about the story, during and after the story. This will engage a child's memory skill.

Stories develop creative thinking and imagination: Storytelling with or without visual aids assists children in developing their creative thinking ability and imagination. These preschool children have to foster their own images and manipulate presented images to manage and make sense of the story, using their imagination. Creativity is imperative, and educators can build on and develop this skill by encouraging children to draw imaginative pictures of characters or settings from the story whilst they are listening to a story.

Stories enhance cultural understanding: Storytelling assists with the enhancement of cultural understanding. It provides children with the opportunity to explore their own culture which an individual develops a sincere and personal relationship with God'. and simultaneously compare it with other cultures (Old Testament and New Testament). Through stories, preschool children learn to empathise with unfamiliar situations, places and people. Stories also help the children to learn more about different values, traditions and life experiences. Storytelling is without doubt a technique to make history alive (to make the Bible alive) and promote further exploration of historical or biblical events.

Story structures improve comprehension: Zealous children comprehend and retain important narrative information and concepts easily when they are presented in story form. Story structures enhance comprehension for all types of narrative texts (Haven 2007:90). The manner of placing information in story form improves the preschool child's comprehension of that material (cf. Haven 2007:91). According to Haven (2007:93), many researchers came to the same conclusion - additional story details certainly support and improve the comprehension of a story. To do this, an effective storyteller must create a real, existential imaginative world for these children by using voice manipulation and including tightly packed and prolific details, in addition to the information and facts in the story (cf. Haven 2007:94). Even humour can be included in the storytelling to attract the attention of preschool children and to get them more interested in the story. ${ }^{20}$

\section{Action and interesting characters (dynamic animation)}

Research, according to Tamminen et al. (1988), pointed out that action and interesting characters and figures that enlighten the storyline facilitate late preschool children to understand religious concepts better. They suggested that preschool children may understand moderate theological concepts even though their religious concepts appear to be limited. This is because they appear not to be as concrete and and factual as older children in their expressions of theological concepts. Finally, preschool children benefit mostly from biblical teachings when they are allowed to create their own meanings of texts and relate them to their lives (cf. Tamminen et al. 1988:61).

\section{Concrete versus abstract}

Piaget ([1951] 1999:118, 131, 152, 205, 213) noted that preschool children have a vibrant imagination. For them, anything seems possible. They do not think logically about the world in the adult sense of logic. Their perceptions of situations, events or certain people are not necessarily incorrect, but could be dissimilar from normal ways older children and adults perceive it. According to Fosarelli (2003:4), causes the 'limited repertoire of life experiences' of these children often to project onto the characters in novels (in this case biblical narratives),

20. See Parrott (1994:36-38) on Humour as a Teaching Strategy and Shiyab (2009:1-9) on Pedagogical Effect of Humor on Teaching. According to Shiyab (2009:1), humour is 'a social phenomenon and a form of communication that should not be disregarded in any learning or teaching environment. It plays a fundamental role in creating harmony and cohesion between students and teachers'. 
'things, or situations of their understanding of previously encountered people, things, or events that they perceive as similar. Such projections can be positive, negative or even neutral' (Fosarelli 2003:4).

\section{Interactive storytelling: Listening to the biblical narrative}

So far in the section, some 'benefits of storytelling' have been briefly dealt with as relating to the character of preschool children. In this subsection, the focus of storytelling is on how 'stories can be communicated' in relation to cartoon animation and educational gaming as part of the communication of the biblical message to preschool children.

The argument in this article is that an effective way of communicating biblical stories to preschool children is to start off with an animated e-character (mostly preferred and will most successfully attract the attention of the child) who is reading or telling the story from a paraphrase translation of the biblical text, which must closely relate the content of the cartoon animation of this story to follow. Paraphrased translations draw on contemporary languages and idioms trying to capture the meaning of the original text. Digital agents (as proposed earlier) are recommended to be used as entertaining for learning, in an e-learning presentation of the story.

The digital agent can communicate the story and can act as a digital operator within strictly defined scenarios to achieve the same effects as that of an empiric and physical storyteller (parent, teacher, etc.). An element of surprise must be present to achieve the same effects and even transcend the performance of an empirical and physical storyteller; the following aspects are critically important: know the audience (preschool children), have a good design (single message and structure), create detailed characters and events, include facts, develop a dramatic tension (cf. Davis 2018:1), be relevant and engage emotion.

Hence, the (animated e-character) storyteller must be aware of how preschool children think and what their needs are. The story must have a good design and should be a suitable conceptual replica of the biblical story (cf. Spierling 2006:118). For preschool children, it should have only a single solid message. It should have a good flexible structure:

- Part 1 - introduce the situation, background, realistic characters (cf. Spierling 2006:118) and obstacle(s) they are going to face, which is for orientation.

- Part 2 - portray how the story deals with the problem or situation.

- Part 3-describe the resolution of the obstacle(s).

The description of characters and events should be colourful and imaginative. The story must conform to the facts in the biblical text. Dramatic tension should be created and be further developed through articulation and intonation using the digital agent. The preschool child must be emotionally engaged in the events of the story. The child should be drawn into the text (story). Finally, each story must have an element of surprise.
After hearing the story ${ }^{21}$ (one or more times), the exact content must be communicated to the children in terms of cartoon animation to give them a visual presentation of what has just now been communicated to them verbally. This will stimulate and improve their comprehension even more.

\section{Cartoon animation of the biblical narrative told}

Effective teaching, par excellence, 'demands a host of devices, techniques and strategies. This is not only to achieve cross critical outcomes, but [equally] because of variety' (Fleischer 2010:1). More effective learning can be aided by varying teaching styles and training media. The approach of simplicity and the use of humour are influential tools that can also be included in 'any learning methodology' (Fleischer 2010:1).

In their research on the use of cartoons in education, Eker and Karadenis (2016:231) pointed out that teaching supported by cartoon animation seems to be more effective than teaching based on traditional methods. The visual presentations of information have proven to be remarkably imperative for the success of the 'educational process' (Dalacosta et al. 2009:741). Therefore, the effectiveness of cartoon animation, as an educational tool, has been augmented. Learning occurs in this mode more visually than orally. The effectiveness of cartoon animations must be seen and acknowledged by all educators and consequently implemented by them. For this purpose, electronic devices (such as overhead projectors, computers, tablets and smartphones) would be useful (cf. Eulie 1969:289).

Abuzahra, Farah and Zalloum (2016:237) convincingly argued that an 'animated cartoon doubles information storage in the brain'. This is because the information embedded in cartoon animations is coded verbally and visually. These codes allow the information to be pictured and remembered, more easily than the abstract information children receive by exclusively listening to the verbal information educators communicate. Cartoon animations create variations in the brain, which help the child construct associations more easily. Bahrani and Sim (2012:56-64) encouraged the use of cartoons (animation). According to Abuzahra et al. (2016:237), cartoons allowed both the hemispheres of the brain to work simultaneously at full capacity. Classical learning, which is orally (listening) oriented, engages only the left side of the brain. After some time, listening typically leads to tediousness, which results in less concentration. The left side of the brain functions to understand the dialogues in the cartoon animation simultaneously with the audio-visual components of the right side of the brain, which work to dissect pictures.

Adults and also children process cartoons promptly because they are 'easy on the eye and easy on the brain' (Fleischer 2010:2). Srikwan and Jacobsson (2007:10) complemented this statement by saying that 'a picture speaks a thousand words', 21.Parents and educators can consider it $50 / 50$ to come to 'first listen to' or 'first hear and see' the story. 
a maxim often used in educational environments to communicate important messages. Fleischer (2010:2) then added that it is widely acknowledged that the majority of people retain almost $75 \%-80 \%$ of visual information. Therefore, we can logically infer that the visual nature of cartoons (especially animation) would cause information to be processed more effectively and efficiently. Education can be boosted more through cartoon animation than through other pictorial media (Fleischer 2010:2). Van Wyk (2011:117) confirmed that '[a]s a teaching strategy, alleged benefits include the promotion of understanding; increased attention and interest; motivation towards learning; improved attitudes; productivity; creativity and divergent thinking'.

With regard to the successful impact of cartoon animation, we definitely have to take cognisance of the important role of constructivism, ${ }^{22}$ as an approach that will not only assist preschool children to learn but also enhance their rational abilities. It enables these children to obtain knowledge. This happens when they are encouraged to associate prior experiences with additional new concepts that they draw from a cartoon animation learning context or environment (Elliott et al. 2000:256). By using cartoon animation, the habitual daily life of these small children can be positively manipulated and pictured in such a way that they can easily combine the cartoon animation content with their acquainted and equivalent experiences (cf. Abuzahra et al. 2016:230). This is only feasible if they can be assisted by their educators, peers or parents instead of doing things on their own (cf. Woodall 2017:28-40).

Eker and Karadenis (2016:232) are convinced that cartoons (animation) provide a more permanent method of learning. The given reasoning showed that audio-visual programmes, in general, are a great source for teaching purposes. Cartoon animations with good storylines will certainly motivate preschool children to capture the language and content of the story more effectively. Consequently, this will have a substantial outcome on language improvement, cognitive development and conduct (cf. Bahrani \& Sim 2012:56) and concept formation of the child.

In light of these recommendations, the author of this article regards the fabrication of cartoon animations (in cooperation with storytelling and educational games) of large parts of the Bible necessary to communicate the biblical message to preschool children. This medium will enable a cartoonist to manipulate the biblical truth to the comprehensive level of preschool children. A good cartoonist can then also incorporate humour at the level of these children to attract their attention and make the biblical story, related to the initial storytelling, interesting and exciting.

Thus, the recommended way to teach a biblical narrative to preschool children is to let the biblical story first be told by a cartoon-animated (E-)agent. After listening to the story, the

22.Constructivism is 'an approach to learning that holds that people actively construct or make their own knowledge and that reality is determined by the experiences of the learner' (Elliott et al. 2000:256). children can watch the cartoon animation of the story on the same electronic device. This can recur a few times considering the need, curiosity and enjoyment of the preschool child. These two activities can then be successively followed by playing some games (developed by a computer game developer) related to the biblical story content on the same device. The games will assist preschool children to (1) understand the meaning and message of the biblical story, (2) remember the content of the biblical story much better and (3) promote conceptualisation.

\section{Educational gaming: Reflection of the content of the biblical story}

This section comprises the third phase of communicating the content of the Bible to preschool children, using technology educational $^{23}$ gaming. According to Spierling (2006:118), storytelling and games complement one another in an educational environment and are, therefore, extensively used and applied in tuition, with or without technology.

Today, video and computer gaming is a multibillion dollar industry, which dynamically expanded exponentially over the past few decades (cf. Amr 2012:21). Numerous scholarly publications have researched the various aspects of video and computer gaming. ${ }^{24}$ The two most debatable aspects to be highlighted are the negative and positive effects of video and computer games (see Rutger et al. 2017:884) on children from various age groups. To participate in the judgement and debate of these games, the following two aspects have to be considered in particular: (1) not to generalise gaming, that is, to holistically refer to or to judge holistically computer games as negatively bad (violent, bad and harmful) or just positively good; and (2) to distinguish between the different genres in gaming (e.g. simulations, action, real-time strategy, puzzle, ${ }^{25}$ sports and education ${ }^{26}$, to name a few; cf. Hurst 2015). Surely, certain genres of gaming can have destructive outcomes over a period of time, as pointed out by numerous scholarly publications (see e.g. Roe \& Dichmeis 2014:268; Rutger et al. 2017:884-889). However, we should not stop here.

Almost all scholarly research ${ }^{27}$ on the genre of educational gaming unanimously accepted that this format of gaming can be utilised in an advantageous manner. This genre is what has been proposed in this article for it relates and

23. Educational refers in this context to the related content of the biblical stories dealt with in the previous two activities.

24.See all the sources used in this subsection and many more on the internet.

25.This book exposes a number of games that can be used for preschool children. One of these games is 'the puzzle', a conundrum primarily designed for entertainment. Many entertaining puzzles have been retailing for the amusement of preschool children. The child need not to draw deep knowledge on any discipline. It only involves the distinguishing of patterns, by using spatial visualisation skills (Moursund 2007:11). For teaching of biblical narratives, electronic puzzles can be a picture of the story to be communicated.

26. Many 'great educational games' already exist in a variety of subjects and disciplines. These educational games can certainly be observed as examples.

27.The following publications support this view: Amr 2012:21-29; Gaydos 2014 159-175; Lobel et al. 2017:884-897; Marklund 2014:7; Moursund 2007; Noemi \& Máximo 2014:230-238; Petrovska et al. 2013:884 and Roe \& Dickmeis 2014 261-272. 
strengthens the objective of this research. Roe and Dichmeis (2014:268) had pointed out a significant amount of published research indicating that the use of computer games in an educational context (also referred to as educational games) can have positive effects on the motivation and skills of children (Roe \& Dichmeis 2014:268). Sálceanu (2014:840) had pointed out that 'computer games ${ }^{28}$ have a large impact on children's development'. She recommended the use of these games for the achievement of certain educational and developmental objectives and activities. ${ }^{29}$ She also recommends that parents should pay necessary attention to protect these preschool children from any harmful effects of computer games.

\section{Educational games: ${ }^{30}$}

- are intentionally designed games used for educating preschool children

- help preschool children to understand concepts and attain knowledge of a pre-determined area

- are used to acquire elementary problem-solving abilities during game playing

- explain (teach) particular concepts, boost cognitive development and apprehend historical events or cultures

- provide a didactic approach to present educational content in a game format

- are electronic computer-based games that usually adhere to the 'constructivist theory of learning'.

According to Marklund (2014:7), a game is a tool but not a solution. Educational games should elevate and facilitate situations for learning. Games should never dominate or be used to replace any existing educational environment. It should be regarded as an opportunity in the education of preschool children to increase learning activities in new directions.

Petrovska, Sivevska and Cackov (2013:884) also regarded educational gaming as a powerful tool for education. Gameplay can, therefore, facilitate preschool children not only to obtain knowledge but also to establish knowledge, augment their experiences and improve skills and habits to imprint the biblical doctrine of discipleship. Gameplay also contributes to a healthier childhood and intellectual development. Games stimulate preschool children to continue searching and exploring in order to discover their own solutions in specific circumstances. This facilitates improvement of their environmental knowledge and human relationships. Through gaming, they adapt their own behaviour to find answers to many questions. Educational games feed curiosity, enrich their imagination, advance accuracy and reflexes and so forth (cf. Petrovska 2013:880; cf. also Hodent 2014:145-146; Domínguez et al.

28.The sophistication of toys is even more evident in the video game consoles and software (also laptops, smartphones and tablets). A growing market of visual and concrete applications is available for the preschool market (Giddings 2014:90).

29.See Montrieux et al. (2015) for 'teaching and learning with mobile technology'.

30.https://www.igi-global.com/dictionary/designing-engaging-educational-gamesand-assessing-engagement-in-game-based-learning/9123.
2013:382; Randel et al. 1992:261-276; Whitebread et al. 2017:25-26). ${ }^{31}$

At the beginning of this article, the objective was to endeavour to point out how technology can be used to communicate the Gospel to preschool children. The modus operandi proposed was to merge and integrate storytelling for preschool children with the use of cartoon animation. These children can then be assisted to play a few basic computer games related to the storytelling and cartoon animation of the particular biblical story communicated. Through these games they can become better acquainted with the biblical content and biblical principles, which can have a permanent influence on their lives. All this can be fun and enjoyable. These games will also facilitate preschoolers to develop some of their basic skills (cf. Domínguez et al. 2013:382), such as phonological awareness, organising in sequence, foundational geometry, memory of numbers, categorisation, sorting of objects by material, classification of living things, matching of opposite words and distinguishing one idea from another (all this applied to the biblical story). The content of the Bible stories communicated to these preschool children must be used and incorporated into the various computer games to add more related, applicable and practical applications of these stories' content. Finally, it is important to influence the emotional area of these children. To achieve this, a 'virtual reward system should always be included to create positive emotions on task completion' (Domínguez et al. 2013:383). This will motivate them to complete the tasks. Achievements may generate positive emotions - they will feel and experience that they are performing well (cf. Domínguez et al. 2013:383).

The three stages presented in this article build on one another and should complement one another. The specific sequence of these three stages in this article has to be the corollary. All games must be computerised and all three activities (interactive storytelling, cartoon animation and gaming) should be made available as a unit and in an integrated computer program. Different kinds of games can be developed by computer experts. ${ }^{32}$ As a result of graphics constraints, already developed games could not be incorporated here, but are available from the author.

\section{Conclusion}

The first section of this article focused on relational development systems to explain how the God-image of preschool children is formed and developed by interaction and relationship with individuals in different contexts. It was observed that the relationship of preschool children with adults influenced their perception and experience of God. This is imperative information, so parents and teachers

31.Noemi and Máximo (2014:230) also referred to 'serious games' as a sub-genre of educational games. For them, serious games can successfully be used for training because of their highly positive outcomes on the learning process. The objective of these games exceeds pure amusement: they 'reinforces learning in a dynamic, interactive, motivating and entertaining way'. Tutoring seems to be a crucial key for interactive, motivating and entertaining way'. Tutoring seems to be a crucial key for facilitating learning processes, guiding participants to achieve their objectives in the game and finally monitoring inappropriate participant behaviour. The focus on learning should lead to considering the profiles of the participants, 'in particular
their previous experience in the field studied'.

32.For more games, which can be adapted for this purpose, see also Bartl (2008) and Morin (2013). 
should be aware that the way they treat these preschool children will have a cause and effect on how the children will perceive the communication of the biblical content.

In the second part of this article the objective was to propose a construct or mode of how the biblical content can be communicated (taught) to preschool children. This construct can assist preschool children to understand and remember the Biblical content probably better and influence their way of living - related to biblical principles and Christian discipleship. The production of an e-orator, who tells a biblical story, a cartoon animation and related educational gaming should be developed and computerised by a team of experts in the fields of biblical teaching, preschool education and cartoon animation. It is important that these three activities be conducted as a single event in the sequence presented in this article.

The motivation behind this approach is that preschool children enjoy listening to stories, watching animated cartoons and playing games every day. The repetition of these three activities is recommended, and the frequency should be determined by the child. These three activities have become fundamental categorical designs and presentations in child education. Therefore, in a postmodern era, parents, the church and Christian nurseries, or any other religious education agents, in general are invited to explore this mode of teaching of the Gospel to (late) preschool children.

\section{Acknowledgements Competing interests}

The author declares that he has no financial or personal relationships that may have inappropriately influenced him in writing this article.

\section{Author's contribution}

D.G.v.d.M. is the sole author of this research article.

\section{Ethical considerations}

This article followed all ethical standards for research without direct contact with human or animal subjects.

\section{Funding information}

This research received no specific grant from any funding agency in the public, commercial or not-for-profit sectors.

\section{Data availability}

Data sharing is not applicable to this article as no new data were created or analysed in this study.

\section{Disclaimer}

The views and opinions expressed in this article are those of the author and do not necessarily reflect the official policy or position of any affiliated agency of the author.

\section{References}

Abuzahra, N., Farah, M.A.-H. \& Zalloum, S., 2016, 'Using cartoon in language classroom from a constructivist point of view', Arab World English Journal 3(1), 229-245. https://doi.org/10.2139/ssrn.2822995

Amr, K., 2012, 'Learning through games: Essential features of an educational game', PhD dissertation, Syracuse University.

Bahrani, T. \& Sim, T.S., 2012, Audio-visual news, cartoons, and films as sources of authentic language input and language proficiency enhancement, viewed 22 March 2020, from http://www.tojet.net/articles/v11i4/1145.

Bartl, A., 2008, 101 Pep-up games for children, refreshing, recharging, refocussing, Hunter House Publishers, Alameda, CA.

Bridges, L.J. \& Moore, K.S., 2002, 'Religion and spirituality in childhood and adolescence', in Child trends, pp. 3-62, viewed 15 August 2020, from https:// www.childtrends.org/wp-content/uploads/2002/01/Child_Trends-2002_01_01_ FR_ReligionSpiritAdol.pdf.

Dalacosta, K., Kamariotaki-Paparrigopoulou, M., Spyrellis, J.A. \& Palyvos, N., 2009, 'Multimedia application with animated cartoons for teaching science in elementary education', Computers \& Education 52(4), 741-748. https://doi. org/10.1016/j.compedu.2008.11.018

Davies, H., 2019, 'Religious devices: A survey of technologies of worship', Communication 17(2), 1-23. https://doi.org/10.7275/2f6f-w963.

Davis, A., 2018, 7 Simple ways to tell a compelling story, Inc. 5000, viewed 08 March 2020, from https://www.inc.com/alison-davis/7-simple-ways-to-tell-acompelling-story.html.

De Roos, S.A., 2006 'Young children's God concepts: influences of attachment and religious socialization in a family and school context', Religious Education 101(1), 84-103.

De Roos, S.A., Miedema, S. \& ledema, J., 2010, 'Young children's descriptions of God: Influences of parents' and teachers' God concepts and religious denomination in schools', Journal of Beliefs and Values 22(1), 19-30.

Domínguez, A., Saenz-de-Navarrete, J., De-Marcos, L., Fernández-Sanz, L., Pagés C. \& Martínez-Herráiz, J.-J., 2013, 'Gamifying learning experiences: Practical implications and outcomes', Computers \& Education 63(1), 380-392. https://doi. org/10.1016/j.compedu.2012.12.020

Dupertuis, R.R., 2012, 'Translating the Bible into pictures', in S. Van der Stichele \& H.S. Pyper (eds.), Text, image, and otherness in children's Bibles, pp. 271-290, Society of Biblical Literature, Atlanta, GA.

Eker, C. \& Karadeniz, O., 2016, 'The effects of educational practice with cartoons on learning outcomes', International Journal of Humanities and Social Science 4(14), 223-234.

Elliott, S.N., Kratochwill, T.R., Littlefield Cook, J. \& Travers, J., 2000, Educationa psychology: Effective teaching, effective learning, 3rd edn., McGraw-Hill College, Boston, MA.

Ettekal, A.V., Burkhard, B., Fremont, E., Su, S. \& Stacey, D.C., 2017, 'Relational developmental systems metatheory', in K. Peppler (ed.), The SAGE encyclopedia of out-of-school learning, pp. 650-651, Sage, Thousand Oaks, CA.

Eulie, J., 1969, 'Creating interest and developing understanding studies through cartoon', Peabody Journal of Education 46(5), 288-290. https://doi. org/10.1080/01619566909537642

Fleischer, J.A., 2010, Using cartoons for type education, viewed 23 March 2020, from http://www.docstoc.com/docs/31863960/Using-Cartoons-for-Type-Education.

Floridi, L., 2014, The 4th revolution: How the infosphere is reshaping human reality, Oxford University Press, Oxford.

Fosarelli, P., 2003, 'Children and the development of faith: Implications for paediatric practice', Contemporary Paediatrics 20(1), 1-11, viewed 13 March 2020, from https://www.contemporarypediatrics.com/article/children-and-developmentfaith-implications-pediatric-practice.

Gaydos, M., 2014, 'Educational video games: Two tools for research and development', in F.C. Blumberg (ed.), Learning by playing: Video gaming in education, pp. 159-175, Oxford University Press, Oxford.

Giddings, S., 2014, Game worlds: Virtual media and children's everyday play Bloomsbury, London.

Haven, K., 2007, Story proof: The science behind the startling power of story, Greenwood Publishing, Westport, CT.

Hodent, C., 2014, 'Toward a playful and usable education', in F.C. Blumberg (ed.), Learning by playing, pp. 145-158, Oxford University Press, Oxford.

Hurst, J., 2015, '12 Types of computer games every gamer should know about', Thought Catalogue, viewed 15 August 2020, from https://thoughtcatalog.com/ jane-hurst/2015/02/12-types-of-computer-games-every-gamer-should-knowabout/.

Jardine, M.M. \& Viljoen, H.G., 1992, 'Fowler's theory of faith development: An evaluative discussion', Religious Education 87(1), 74-85. https://doi. org/10.1080/0034408920870108

Johnson, S.K., Bowers. E.P., Hershberg, R.M. \& Geldhof, G.J., 2013, 'Relational developmental systems theories of positive youth development: Methodological issues and implications' in Handbook of developmental systems theory \& methodology, pp .66-94, Guilford, New York, NY.

Jones, T.P., 2004 'The basis of James W. Fowler's understanding of faith in the research of Cantewell Smith: An examination from an evangelical perspective', Religious Education 99(4), 345-357. https://doi.org/10.1080/00344080490513171 
Kanakanui, L.-P.P., 2017, 'Faith development as experienced by Christian high school seniors', unpublished PhD dissertation, Liberty University.

King, P.E. \& Boyatzis, C.J., 2015, 'Religious and spiritual development', in M.E. Lamb \& R.M. Lerner (eds.), Handbook of child psychology and developmental science, pp. 247-1021, John Wiley \& Sons, Hoboken, NJ.

Kolawole, O.P., 2019, 'An evaluation of the use of technology in the 21st century Nigerian Church', Pharos Journal of Theology 100(1), 1-8.

Kuther, T.L., 2016, Lifespan development: Lives in context, Sage, London.

Lin, D., Zhang, J. \& McBride-Chang, C., 2010, 'Literacy acquisition and impairment in young children', in L. Colombo \& R. Bianchi (eds.), Preschool children: Physical activity, behavioral assessment and developmental challenges, pp 1-18, Nova Science Publishers, New York, NY.

Lobel, A., Engels, R.C.M.E., Stone, L.L., Burk, W.J. \& Granic, I., 2017, 'Video gaming and children's psychosocial wellbeing: A longitudinal study', Journal of Youth Adolescence 46(4), 884-897. https://doi.org/10.1007/s10964-017-0646-z

Marklund, B.B., 2014, 'Working with educational games', PhD dissertation, University of Skövde, Skövde.

Merriam-Webster Dictionary, 2020, Technology, viewed 13 June 2020, from https:// www.merriam-webster.com/dictionary/technology.

Mohler, A., 2020, 'Liberal theology', Monergism, viewed 23 July 2020, from https:// www.monergism.com/topics/bad-theology/liberal-theology.

Montrieux, H., Vanderlinde, R., Schellens, T. \& De Marez, L., 2015, 'Teaching and learning with mobile technology: A qualitative explorative study about the introduction of tablet devices in secondary education', PLOS One 10(12), e0144008. https://doi.org/10.1371/journal. pone.0144008

Moore, K., Gomez-Garibello, C., Bosacki, S. \& Talwar, V., 2016, 'Children's spiritual lives: The development of a children's spirituality measure', Religions 7(95), 1-11. https://doi.org/10.3390/rel7080095

Morin, A., 2013, The everything kids' learning activities book: 145 entertaining activities and learning games for kids, Adams Media, Avon, MA.

Moursund, D., 2007, Introduction to using games in education: A guide for teachers and parents, viewed 02 August 2020, from https://pages.uoregon.edu/moursund/ Books/Games/ Games.pdf.

Mumford, L., [1934] 2010, Technics and civilization, viewed 17 March 2020, from https://archive.org/details/in.ernet.dli.2015.49974/page/n9/mode/2up.

Myers, P., 2012, Storytelling for children, Child Development Institute, viewed 18 March 2020, from https://childdevelopmentinfo.com/child-activities/storytellingfor-children/\#gs.zo7hfu.

Noble, D.F., 1997, The religion of technology: The divinity of man and the spirit of invention, Alfred A. Knopf, New York, NY.

Noemi, P.-M. \& Máximo, S.H., 2014, 'Educational games for learning', Universa Journal of Educational Research 2(3), 230-238. https://doi.org/10.13189/ ujer.2014.020305

Overton, W.F., 2013, 'A new paradigm for developmental science: Relationism and relational-developmental systems', Applied Developmental Science 17(2), 94-107. https://doi.org/10.1080/10888691.2013.778717

Parette, H.P. \& Blum, C., 2013, Instructional technology in early childhood, Paul H. Brooks Publishing Co., London.

Parrott, T., 1994, 'Humour as a teaching strategy', Nurse Educator 19(3), 36-38. https://doi.org/10.1097/00006223-199405000-00017

Petrovska, S., Sivevska, D. \& Cackov, C., 2013, 'Role of the game in the development of preschool child', Procedia - Social and Behavioural Sciences 92(1), 880-884 https://doi.org/10.1016/j.sbspro.2013.08.770

Piaget, J., [1951] 1999, Play, dreams and imitation in childhood, Routledge, London.
Randel, J.M., Morris, B.A., Wetzel, C.D. \& Whitehill, B.V., 1992, 'The effectiveness of games for educational purposes: A review of recent research' Simulation \& Gaming 23(3), 261-276, https://doi.org/10.1177/1046878192233001

Ratcliff, D., 1988, 'The cognitive development of preschoolers', in D. Ratcliff (ed.), Handbook of preschool religious education, pp. 7-29, Religious Education Press, Birmingham.

Roe, K. \& Dickmeis, A., 2014, 'Computer games and education: A multidimensional relationship', in F.C. Blumberg (ed.), Learning by playing: Video gaming in education, pp. 261-272, Oxford University Press, Oxford.

Roehlkepartain, E.C., King, P.E. \& Benson, P.L., 2006, The handbook of spiritual development in childhood and adolescence, Sage, New Delhi.

Rogers, C.M. \& Fewell, D.N., 2012, 'No greater love: Jonathan and his friendship with David in text, tradition, and contemporary children's literature', in S. Van der Stichele \& H.S. Pyper (eds.), Text, image, and otherness in children's Bibles, pp. 123-152, Society of Biblical Literature, Atlanta, GA.

Rutger, A.L., Engels, C.M.E., Stone, L.L., Burk, W.J. \& Granic, I., 2017, 'Video gaming and children's psychosocial wellbeing: A longitudinal study', Journal of Youth and Adolescence 46(1), 884-897. https://doi.org/10.1007/s10964-017-0646-z

Sálceanu, C., 2014, 'The influence of computer games on children's development. Exploratory study on the attitudes of parents', Procedia - Social and Behavioural Sciences 149(1), 837-841. https://doi.org/10.1016/j.sbspro.2014.08.323

Shaffer, D.W., 2006, How computer games help children learn, Palgrave Macmillan, New York, NY.

Shiyab, S., 2009, 'Pedagogical effect of humour on teaching', Digital stream proceedings, United Emirates University, pp. 1-9, viewed 28 April 2020, from https://www. academia.edu/698395/Pedagogical_Effect_of_Humor_on_Teaching.

Sims, D.B., n.d., The effect of technology on Christianity: Blessing or curse?, Broadman Publishing, viewed 06 March 2020, from https://www3.dbu.edu/Naugle/pdf/ The\%20Effect\%20of\%20Technology\%20on\%20Christianity2.pdf.

Spierling, U., 2006, 'Learning with digital agents - Integration of simulations, games, and storytelling', in M. Burmester, D. Gerhard \& F. Thissen (eds.), Digital game based learning, Proceedings of the 4th international symposium for information design, pp. 115-148, Universitätsverlag, Karlsruhe.

Srikwan, S. \& Jakobsson, M., 2007, Using cartoons to teach internet security, School of Informatics, Indiana University, Bloomington, MN.

Stahl, W., 1999, God and the chip: Religion and the culture of technology, Wilfrid Laurier University Press, Waterloo.

Tamminen, K., Vianello, R., Jaspard, J.-M. \& Ratcliff, D., 1988, 'The religious concepts of preschoolers', in D. Ratcliff (ed.), Handbook of preschool religious education, pp. 59-81, Religious Education Press, Birmingham.

Tippins, D.J., Nichols, S.E. \& Kemp, A., 1999, Cultural myths in making: The ambiguities of science for all, ERIC, viewed 23 July 2020, from https://eric. ed.gov/?id=ED446916.

Vander Stichele, C. \& Pyper, H.S., 2012, Text, image, and otherness in children's Bibles: What is in the picture, Society of Biblical Literature, Atlanta, GA.

Van Wyk, M.M., 2011, 'The use of cartoons as a teaching tool to enhance student learning in economics education', Journal of Social Science 26(2), 117-130. https://doi.org/10.1080/09718923.2011.11892888

Vygotsky, L.S., 1978, Mind in society: The development of higher psychological processes, Harvard University Press, Cambridge, MA.

Whitebread, D., Neale, D., Jensen, H., Liu, C., Solis, S.L., Hopkins, E. et al., 2017 The role of play in children's development: A review of the evidence (research summary), The LEGO Foundation, Billund.

Woodall, C. 2017, Reimagining the role of technology in education: 2017 nationa education technology plan update, U.S. Department of Education, viewed 13 August 2020, from https://tech.ed.gov/files/2017/01/NETP17.pdf. 